F. Reprod. Fert. (1967) 14, 365-372

\title{
EFFECT OF GONADOTROPHINS ON THE SECRETION OF PROGESTERONE AND OESTROGENS BY THE SHEEP OVARY PERFUSED IN SITU
}

\author{
E. DOMAŃSKI, L. SKRZECZKOWSKI, E. STUPNICKA, \\ R. FITKO AND W. DOBROWOLSKI \\ Institute of Animal Physiology and Nutrition, \\ Jablonna, near Warsaw, Poland
}

(Received 22nd July 1966; revised 10th September 1966)

\begin{abstract}
Summary. The effect of gonadotrophins on the secretion rate of gonadal hormones in sheep was investigated by perfusing the ovary in situ with luteinizing hormone (LH), luteotrophic hormone (LTH) and follicle stimulating hormone (FSH). The gonadotrophins were infused through the side branch of the ovarian artery and the effluent blood was collected from the utero-ovarian vein. Perfusion of the ovary on the 8th day of the oestrous cycle with LH or LTH resulted in the increase of the secretion rate of progesterone within 20 to $30 \mathrm{~min}$ after the beginning of the perfusion; when the perfusion of the ovary was terminated the rate of progesterone secretion reverted to the original level within 20 to $30 \mathrm{~min}$. Unlike LH and LTH, FSH infused on the 8th day of the oestrous cycle decreased the output of progesterone. On the 15th day of oestrous cycle progesterone could not be detected in the effluent blood from the ovarian vein. At that time, perfusion of the ovaries with gonadotrophic hormones produced no effect on the secretion rate of progesterone.

Substances giving positive reaction with Barton's reagent and showing chromatographic characteristics of oestrone and oestradiol were detected in the ovarian venous blood in few animals only, and in very low concentrations. No relation was observed between the presence of these substances in the ovarian venous blood and either the phase of oestrous cycle or the type of gonadotrophin infused. Furthermore, perfusion of the ovary with FSH or LH resulted in the appearance in the ovarian venous blood of an unknown oestrogen-like substance of higher polarity than that of oestrone but lower than that of oestradiol.
\end{abstract}

\section{INTRODUCTION}

In most experiments on the effect of gonadotrophic hormones on the function of ovaries in living animals, these hormones had been administered subcutaneously, intramuscularly or intravenously into the peripheral blood, e.g. by Hilliard, Endröczi \& Sawyer (1961) in rabbits; Hayward, Hilliard \& Sawyer (1963) in Macacus rhesus; Telegdy \& Endröczi (1961) in dogs; and Short, 
McDonald \& Rowson (1963) in sheep. Such procedures, however, enable one to follow the response of the ovaries only at the time of gonadotrophin administration. Moreover, the administration of gonadotrophin into the general blood circulation may result in some other effects. In the present study, the effect of gonadotrophins on the ovary was examined by the method of perfusion of this organ in situ. In this way it was possible to avoid the above-mentioned disadvantages as well as the difficulties inherent in the method of perfusing an organ in vitro.

\section{MATERIALS AND METHODS}

The investigation was carried out on ewes 2 to 4 years old, of the Polish Łowicka breed, in acute experiments under nitrous oxide anaesthesia. Perfusion of the ovaries was carried out on the 8th and 15th day of the oestrous cycle. The method of perfusion entailed the administration of the trophic hormones into the side branch of the ovarian artery, and collection of the venous blood effluent from the utero-ovarian vein; the uterine cranial vein and all other small uterine veins draining to the ovarian vein were clamped off (Plate 1). A substance infused in this manner under low pressure can enter the bloodstream of the ovarian artery and thus be transmitted directly into the ovary. At the same time it is prevented from entering the general blood circulation so that its action is limited to the perfused ovary alone. The details of the method of perfusion of the ovary in the ewe are described elsewhere (Domański \& Dobrowolski, 1966). The preparations of gonadotrophic hormones used were as follows: FSH, NIH-s-2 ovine; LH, NIH-s-7 ovine; LTH, 'Calbiochem' ovine, B grade $(1 \mathrm{mg}=22 \mathrm{i} . \mathrm{u}$.). To prevent blood clotting in the sheep during collection of the ovarian blood, heparin (25,000 i.u.) was administered intravenously. The effluent blood from the ovary was collected before, during and for some time after the infusions of the trophic hormones. The effluent blood from the ovary, obtained at appropriate time intervals, was centrifuged immediately after collection and the plasma separated; the blood cells were then resuspended in isotonic saline $(0 \cdot 1$ volume $)$, the suspension was centrifuged and the supernatant was added to the plasma. The blood cells themselves were resuspended in saline and infused into the jugular vein of the ewe so as to replace the blood which had been lost during the perfusion of the ovary. The blood plasma was stored in polyethylene bottles at $-15^{\circ} \mathrm{C}$ until it could be assayed for the content of gonadal hormones. Progesterone, oestrogens and some of their metabolites were determined.

\section{Determination of gonadal hormones in the plasma of ovarian venous blood}

Progesterone was determined as 2,4-dinitrophenylhydrazone using the method of Stupnicki (1964), modified by Stupnicka (unpublished). This modification consisted in additional purification of crude neutral extracts of blood plasma by means of column partition chromatography on the Celite. Progesterone $\left[4-{ }^{14} \mathrm{C}\right]$ was included as an internal recovery standard; its recovery was on average $52 \%$; the sensitivity was shown to be $0.5 \mu \mathrm{g}$ of progesterone, and the error was 0.2 to $0.4 \mu \mathrm{g}$, when the quantity of progesterone in the sample was 0.5 to $12.0 \mu \mathrm{g}$. 
PLATE 1

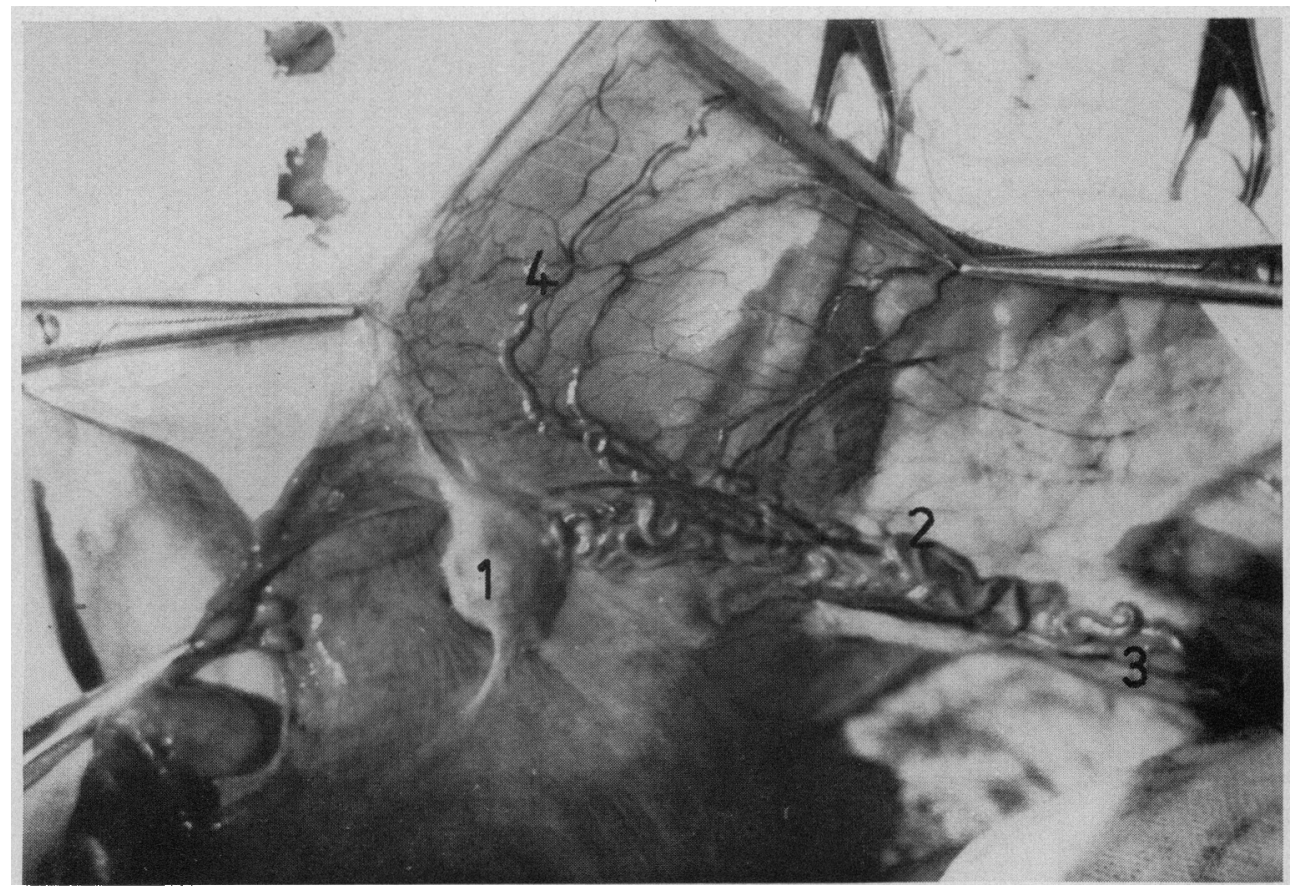

r

The vascularization of the ovary in sheep. 1, the ovary; 2 , the ovarian plexus; 3 , the utero-ovarian vein; 4. side branch of the ovarian artery. 
Oestrogens were determined as follows. The plasma was diluted with water $(1: 6)$, then anhydrous sodium sulphate $(13 \% \mathrm{w} / \mathrm{v})$ and sulphuric acid $(3.2 \%$ $\mathrm{v} / \mathrm{v}$ ) were added and the mixture was heated on a boiling water bath, under a reflux condenser, for $1 \mathrm{hr}$. After cooling, the material was filtered, and both the precipitate and the filtrate then extracted 4 times with ethyl ether (each extraction with half the volume of the diluted plasma). The combined ether extracts were washed with carbonate solutions and then with water, evaporated to dryness and the residue fractionated into the oestriol and oestrone-oestradiol fractions according to the method described by Brown (1955). Both fractions were made strongly alkaline by adding $\mathrm{NaOH}$ to the concentration of $4 \%$ $\left(\mathrm{w} / \mathrm{v}\right.$ ) and then the $\mathrm{pH}$ adjusted to about 10.0 by adding solid $\mathrm{NaHCO}_{3}$. The oestrone-oestradiol fraction was then extracted with benzene $(3 \times 8 \mathrm{ml})$, the benzene extract was washed with water and applied to a column. The 'oestriol' fraction was extracted with ethyl ether $(3 \times 40 \mathrm{ml})$, evaporated to dryness, the residue dissolved in ethanol $(0.25 \mathrm{ml})$ and transferred with benzene $(2 \times 12 \mathrm{ml})$ to another column. The column adsorption chromatography was carried out in tubes (Quickfit \& Quartz Ltd, Cat. No. 12/30) $1 \mathrm{~cm}$ in diameter and approximately $30 \mathrm{ml}$ in volume, filled with $2 \mathrm{~g}$ of alumina prepared according to Brown (1955). The elution from the columns was carried out as follows: the column containing the oestrone-oestradiol fraction was eluted with $8 \mathrm{ml} 1.4 \%$

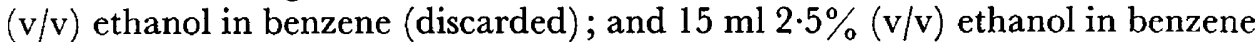
(collected). The column containing the oestriol fraction was eluted with $8 \mathrm{ml}$

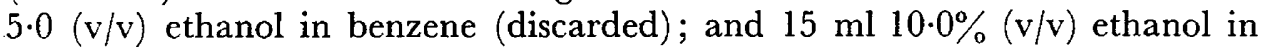
benzene (collected). The eluates were evaporated, the residues dissolved in methanol, and applied to the paper. Paper chromatography was carried out in glass jars (of a similar type to those used for anaerobic bacterial cultures) according to the method of Stupnicki (1964), using short strips $(210 \times 24 \mathrm{~mm})$ prepared from Whatman No. 20 filter paper as described by Matthias (1954a, b). The paper chromatographic systems were: for the oestrone-oestradiol fraction, heptane-benzene-methanol-water $(67: 33: 60: 40)$ at $37^{\circ} \mathrm{C}$ (Bush, 1952) for $1.5 \mathrm{hr}$; for the oestriol fraction, toluene-ethyl acetate-methanolwater $(7: 3: 5: 5)$ at $37^{\circ} \mathrm{C}$ for $1.5 \mathrm{hr}$ (Bush, 1952).

The position of the oestrogen-like substances extracted from blood plasma was determined by cutting off narrow strips from chromatograms and detecting the spots with the reagent of Barton, Evans \& Gardner (1952). Reference spots of the appropriate standards were detected by means of the Folin and Ciocalteu reagent according to the method of Mitchell (1952). Oestrogens were measured by the Ittrich (1958) extraction of Kober chromogens, as modified by Salokangas \& Bulbrook (1961), and using one-third of the quantities of reagents as compared to the original procedure.

\section{RESULTS}

The effect of gonadotrophins on the secretion rate of progesterone by the perfused ovary

The effect of gonadotrophic hormones on the secretion rate of progesterone by the perfused ovary on the 8th day of the oestrous cycle (when the corpus luteum is at the peak of activity) is illustrated in Text-figs. 1 to 3. Secretion 
rates of progesterone and ovarian blood flow rates for individual ewes are given. The differences between the individual ewes were too large to justify a combined statistical evaluation.

Text-figure 1 shows that the perfusion of the ovary in situ with LH on the 8th day of the oestrous cycle increased the output of progesterone; this increase occurred within 20 to $30 \mathrm{~min}$ after the beginning of the perfusion. After the perfusion with $\mathrm{LH}$ was stopped the output of progesterone reverted to low values within 20 to $30 \mathrm{~min}$. A similar effect on the output of progesterone was observed in the perfusion experiments with LTH (Text-fig. 2). However, perfusion of the
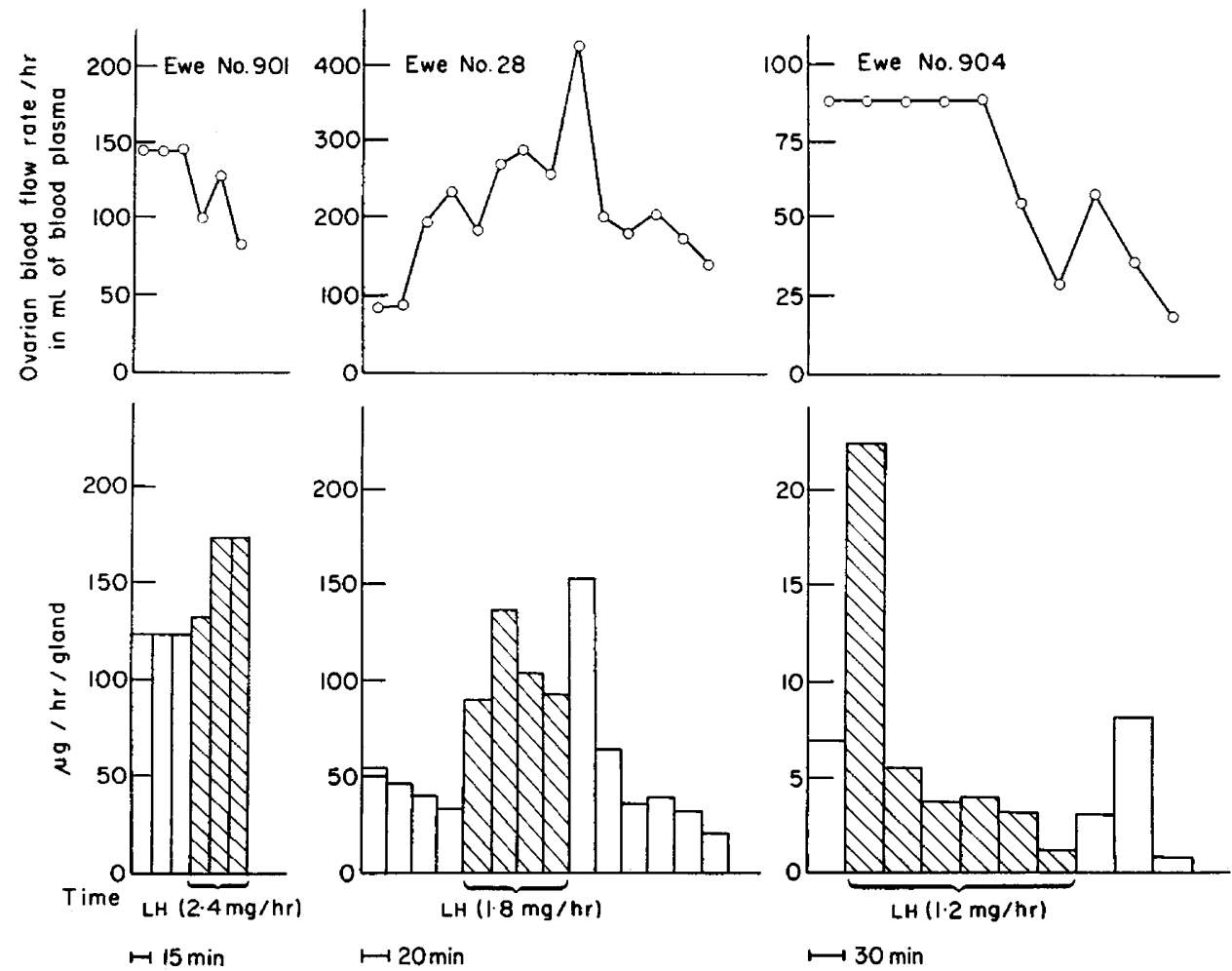

TeXT-FIG. 1. Diagrams showing the effect of LH on the output of progesterone by perfused ovary on the 8th day of the sexual cycle. Hatched columns represent secretion rates of progesterone during perfusion of the ovary with $\mathbf{L H}$, while white columns represent these values before and after perfusion has been terminated. Upper graphs show blood flow rates of perfused ovary.

ovary with FSH on the 8th day of the oestrous cycle appeared to depress the output of progesterone (Text-fig. 3). This effect developed gradually and persisted even when the perfusion had been stopped.

On the 15th day of the oestrous cycle, at the time when the sheep ovary contains involuting corpora lutea and completely developed Graafian follicles, progesterone was not detected in the effluent blood from the ovarian vein; perfusion of such ovaries with gonadotrophic hormones in six ewes had no effect on the secretion rate of progesterone. 
The effect of gonadotrophins on the secretion rate of oestrogens by perfused ovary

Oestrogenic hormones were determined in the ovarian blood plasma of six ewes, in which the ovaries were perfused with LH (four ewes on the 8th, and two ewes on the 15th day of the cycle); and of six ewes, in which the ovaries were perfused with FSH (two ewes on the 8th day, and four ewes on the 15th day of the cycle). The blood samples intended for the determination of oestrogens were collected for a longer time than those for the determination of progesterone, namely, for 45 to $90 \mathrm{~min}$. The volumes of the blood plasma samples were 50 to $220 \mathrm{ml}$.
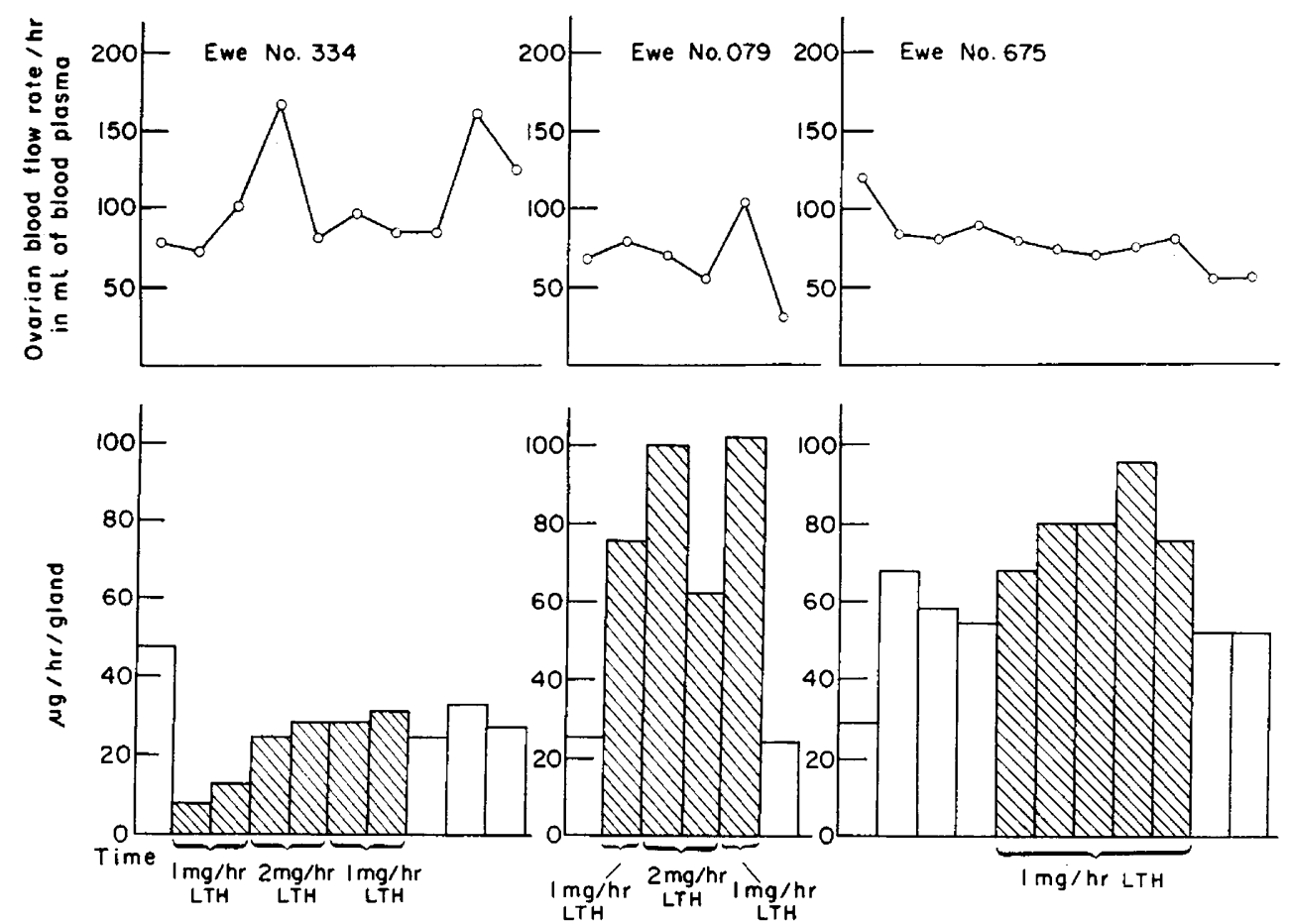

Text-Fig. 2. Diagrams showing the effect of LTH on the output of progesterone by perfused ovary on the 8th day of the sexual cycle. Hatched columns represent secretion rates of progesterone during perfusion of the ovary with LTH, while white columns represent these values before and after perfusion has been terminated. Upper graphs show blood flow rates of perfused ovary.

The oestrone-oestradiol fraction. The substances which gave a positive Barton reaction and behaved chromatographically like oestrone or oestradiol in respect of mobility, were detected in only a few animals, and in very low amounts (very close to the limit of sensitivity of the method used $-0.5 \mu \mathrm{g} / 100 \mathrm{ml}$ blood plasma). Moreover, no relation was observed between the presence of these substances in the blood plasma and either the phase of oestrous cycle or the kind of gonadotrophin used for perfusion of the ovary. The amounts of the substances were too small to permit further characterization. In addition, the oestrone-oestradiol fraction of the ovarian venous blood from the FsH- and LH-treated ewes contained an unknown substance which gave the colour 
reactions with Barton and Folin-Ciocalteu reagents, its polarity intermediate between that of oestradiol-17 $\beta$ and oestrone. The chromatographic mobility of this substance was 0.76 to 0.79 of that of oestrone, and it was similar to that of equilenin; its other characteristics, however, were different from those of equilenin. It was not found in the peripheral blood of sheep at any period of the oestrous cycles, nor was it found in ovarian blood on the 8th day of the cycle in ewes which had not been stimulated with gonadotrophins. The same

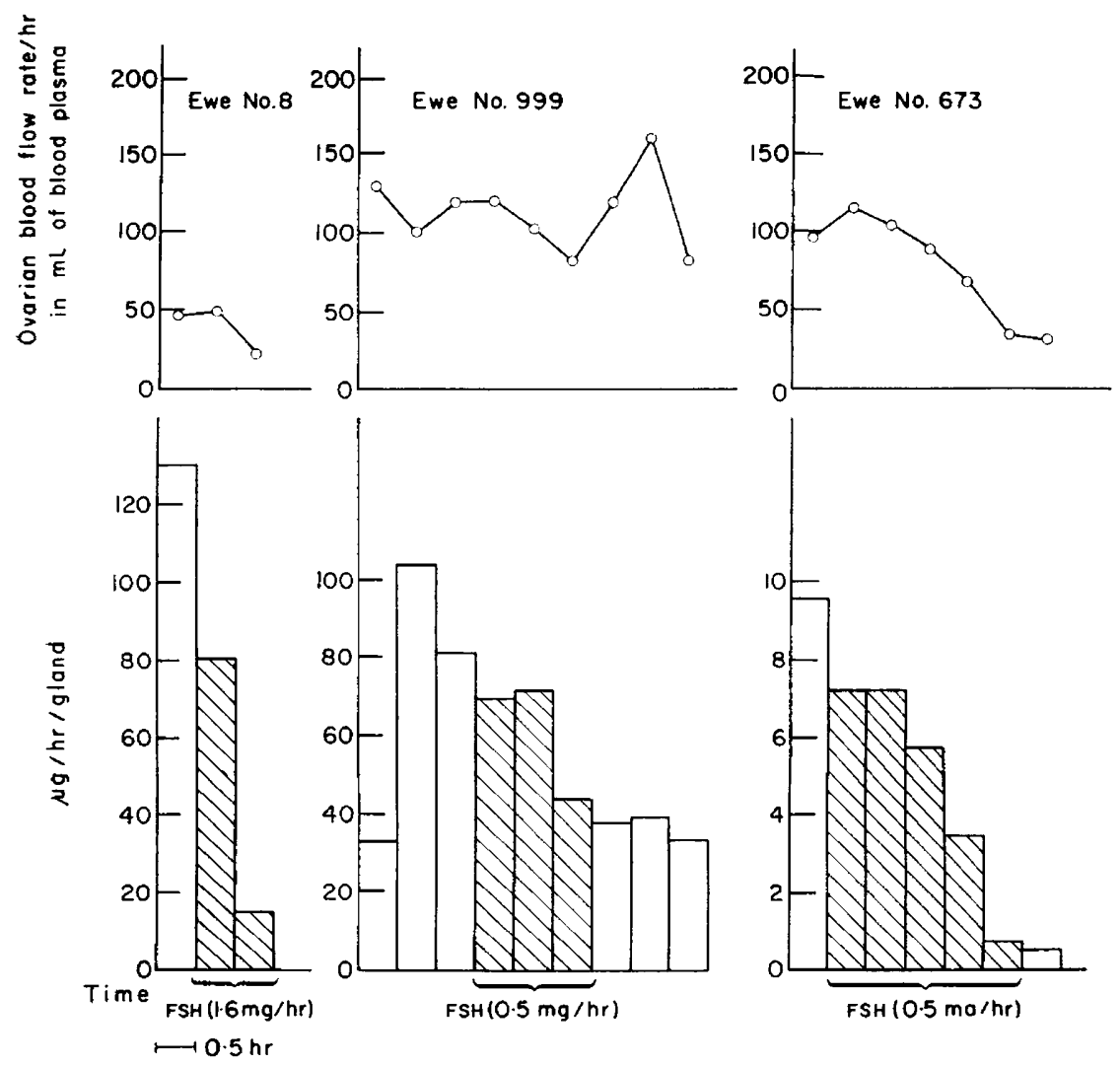

TEXT-FIG. 3. Diagrams showing the effect of FSH on the output of progesterone by perfused ovary on the 8th day of the sexual cycle. Hatched columns represent secretion rates of progesterone during perfusion of the ovary with FSH, while white columns represent these values before and after perfusion has been terminated. Upper graphs show blood flow rates of perfused ovary.

substance, however, was found to occur in very low amounts in ovarian blood on the 15th day of the cycle in two out of the six ewes investigated, even though these animals were not subjected to gonadotrophin treatment. In ewes perfused on the 8th and 15th day of the cycle, this substance was detectable in ovarian blood after both FSH and LH treatment. In FSH-perfused animals it appeared within 20 to $30 \mathrm{~min}$ after the beginning of the perfusion, while in LH-perfused animals it was not detectable until 90 min from the beginning of the perfusion.

The perfusion of the ovary with LTH or with egg-white albumin did not cause 
the appearance of this substance in the ovarian venous blood. Experiments on the chemical identification of this substance are now being carried out.

\section{DISCUSSION}

The behaviour of the secretion rate of progesterone during perfusion of the ovary with trophic hormones indicates that the secretory output of the ovary is closely related in time to the action of gonadotrophins; the rate rises quickly at the time of administration of the $\mathbf{L H}$, for instance, but declines within 20 to $30 \mathrm{~min}$ after the infusion of this hormone had been terminated. Thus, the present study has shown that it is possible to demonstrate not only an increased output of gonadal hormone by the sheep ovary during perfusion with gonadotrophic hormone but even a decreased output of this hormone when the infusion stops. When introducing a trophic hormone into the general blood circulation of an organism it is not known how long this hormone remains active there and, therefore, the response of a target organ to its trophic hormone administered in this way, can not be strictly determined.

The phenomenon of a close relation in time between the action of gonadotrophic hormones and the secretion rate of the ovary presented here may explain our finding of a stimulatory effect of LTH on the output of progesterone by the corpus luteum of the sheep, whereas, to date, this gonadotrophin has only been reported to show luteotrophic effects in rats and mice.

Noteworthy also is the decrease of the output of progesterone which occurs during perfusion of the ovary with FSH. These results are not in agreement with those of Short et al. (1963) who obtained an increase in the secretion rate of progesterone by the ovary on 15th day of the cycle in sheep after intravenous injection of FSH. In our experiments on perfusion of the ovary on 15th day of the cycle, when the ovaries contained involuting corpora lutea and developed Graafian follicles, progesterone was not detected in the effluent ovarian blood in any of the six perfused ewes. As far as the reaction of the ovary to perfusion with FSH is concerned, our results showing a decrease of the secretion rate of progesterone during and after perfusion of the ovary may be assumed to be reliable. If so, this phenomenon would suggest that the release of FsH (at a proper time) in the sexual cycle may influence the ability of the cyclical corpus. luteum to secrete progesterone and its ability to survive.

The fact that some animals (ewes Nos. 904 and 673) showed very low secretion rates of progesterone needs comment; unfortunately it is difficult to interpret these findings. However, we would like to add that in other experiments also on ewes (not yet published) we also found cases with similar low output of progesterone in effluent ovarian blood. Furthermore, the response of the ewe 904, with a low secretion rate of progesterone, to stimulation of the ovary with LH throws some light on this event. The output of progesterone in this ewe increased quickly immediately after the beginning of infusion of LH, but this increase was observed during the first $30 \mathrm{~min}$ of stimulation only, and thereafter the output of progesterone decreased progressively. This response suggests that the animal showed high reactivity to LH stimulation but low capacity for progesterone secretion. Thus, these facts would indicate that the 
low secretion rates of progesterone in some ewes may be due to individual variation.

The new oestrogen-like compound, not identified as yet, is interesting on several accounts. Its appearance in response to FSH or LH, but not to LTH stimulation, and its absence in the ovarian blood plasma on the 8th day of the oestrous cycle before gonadotrophic stimulation, suggests that this substance may be of some physiological significance.

Turning once more to the advantages of the method used in this work, it is worth mentioning that the perfusion method, which makes it possible to determine the relation in time between the action of trophic hormone and the function of its target organ, should be of special value in future investigations of the pituitary-gonadal relationships in ruminants, where the low levels of gonadotrophic and gonadal hormones makes such a study difficult. Moreover, this method should make it possible to investigate the secretion of an ovary with functional disturbances, e.g. a persistent corpus luteum, cystic ovaries or other pathological conditions.

\section{ACKNOWLEDGMENTS}

We would like to express our thanks to Professor W. Klyne for the supply of steroids from Medical Research Council, Steroid Reference Collection, London, and to the National Institutes of Health, Bethesda, Maryland, U.S.A., for the supply of gonadotrophins FSH and LH.

\section{REFERENCES}

Barton, G. M., Evans, R. S. \& Gardner, J. A. F. (1951) Paper chromatography of phenolic substances. Nature, Lond. 170, 249.

Brown, J. B. (1955) A chemical method for the determination of oestriol, oestrone and oestradiol in human urine. Biochem. F. 60, 185.

Busr, I. E. (1952) Methods of paper chromatography of steroids applicable to the study of steroids in mammalian blood and tissue. Biochem. 7. 50, 370.

Domański, E. \& Dobrowolski, W. (1966) Perfusion of ewe's ovary in situ. Endokr. pol. 17, 187.

Hayward, J. N., Hilliard, J. \& Sawyer, Ch. H. (1963) Preovulatory and postovulatory progestins in monkey ovary and ovarian vein blood. Proc. Soc. exp. Biol. Med. 113, 256.

Hilliard, J., Endröczi, E. \& Sawyer, Ch. H. (1961) Stimulation of progestin release from rabbit ovary in vivo. Proc. Soc. exp. Biol. Med. 108, 154.

Iттrich, G. (1958) Eine neue Methode zur chemischen Bestimmung der östrogenen Hormone in Harn. Hoppe-Seyler's Z. physiol. Chem. 312, 1.

Matthias, W. (1954a) Uber ein papierchromatografisches Verfahren für Serienuntersuchungen in der Pflanzenzüchtung. Züchter, 24, 313.

Matthias, W. (1954b) Serienuntersuchungen mit Hilfe einer neuen Form der Streifen-Papierchromatographie. Naturwissenschaften, 1, 17.

Mrtchell, F. L. (1952) Chromatographic isolation and estimation of the natural oestrogens from tissue. Nature, Lond. 170, 621.

Salokangas, R. A. A. \& Bulbrook, R. D. (1961) The determination of small quantities of urinary oestrone, oestradiol-17 $\beta$ and oestriol using Ittrich's extraction method. F. Endocr. 22, 47.

Short, R. V., McDonald, M. F. \& Rowson, L. E. A. (1963) Steroids in the ovarian blood of ewes before and after gonadotrophic stimulation. F. Endocr. 26, 155.

Stupnicki, R. (1964) Determination of ketosteroids in the form of their 2,4-dinitro phenyl-hydrazones in biological material. Acta physiol. pol. 15, 713.

Telegdy, G. I. \& Endröczi, E. (1961) Progesterone content of the dog's ovarian venous blood and ovarian tissue. Acta physiol. hung. 21, 339. 